\title{
Experimental Study on Friction of Hydraulic Cylinder in Different Sealing Systems
}

\author{
Ke Ma ${ }^{1,2}$, Jiawei Wang ${ }^{1}$, Le Gu ${ }^{3}$ \\ ${ }^{1}$ College of Mechanical\& Electrical Engineering, Hohai University, Changzhou 213022, China \\ 2 Jiangsu Key Laboratory of Special Robot Technology, Changzhou 213022, China \\ ${ }^{3}$ BOSCH Rexroth (Changzhou) Co., Ltd, China, Changzhou 213164, China
}

\begin{abstract}
The friction of the hydraulic cylinder mainly comes from the sealing part, the existence of friction leads the wear of the seal. In view of the serious impact of the damage of the seal on the hydraulic cylinder, a set of sealing test system was designed, for the purpose of investigation and analysis on the performance of different sealing kit configuration, in terms of friction with given hydraulic medium. In this paper, there will be the introduction of the principles, constitutions and functions of the testing system. The experimental results provide data support for the design and selection of sealing system of the hydraulic cylinder.
\end{abstract}

\section{Introduction}

As the actuator of hydraulic system, hydraulic cylinder is of wide application in kinds of engineering mechanics because of its simple structure and reliable operation[1]. While in the practical application of engineering mechanics, the problems such as crawling, insufficient output and poor pressure-holding causing by cylinder oil leakage seriously affect the stability, reliability and service life of the device[2]. In the process of the use of hydraulic cylinder, there exists some problems like oil waste, environmental pollution, service life shortening, machine downtime growth, reduction of the production efficiency, cost growth and production failure due to the damage to the seals[3-5].

Although the hydraulic cylinders of Bosch Rexroth have a common standard or professional range of products, but with the use of the field becomes wider, the use requirements become more different, in order to enable enterprises in the fierce market competition are still in a favorable position, and make the product can adapt to the huge market and own the high flexibility and adaptability, companies need to enhance the scientific design of the product, but also to ensure the quality of the case to reduce costs, with the lowest input to get the best results, the traditional choice can not meet these requirements, so exploratory of the experimental study of product components to grasp the performance is imperative[6-9].
The Methods section details the theoretical or experimental methods used. What justifies using a given method? What is special, unexpected, or different in your approach? If you use a standard or usual procedure, mention that upfront, too.

For the sealing performance test, a double rod hydraulic cylinder is designed as the test cylinder, because of the two rods on both sides of the piston, it is for two-way hydraulic drive. And at the meantime, the piston group was designed as the piston and piston rod one-piece, it aims to ensure the alignment of the piston and piston rod, guarantee the same working situation exactly in addition. The foot mounting is chosen to fix the hydraulic cylinder on the floor to process the horizontal test. And the cylinder head is connected with the cylinder tube by screw, the sealing flange are attached to both ends of the hydraulic cylinder. In addition, the displacement sensor is built in the piston rod.

As is shown in Figure 1, the piston and piston rod is one-piece, and the hydraulic cylinder seal is installed in the sealing flange, and the sealing flange is connected with the cylinder head by screw, the foot is threaded connection with the cylinder tube, at the meantime, to control the position of the piston rod, the displacement sensor is installed inside of the piston rod.

\section{Design of Test System}

\subsection{The design of hydraulic cylinder}




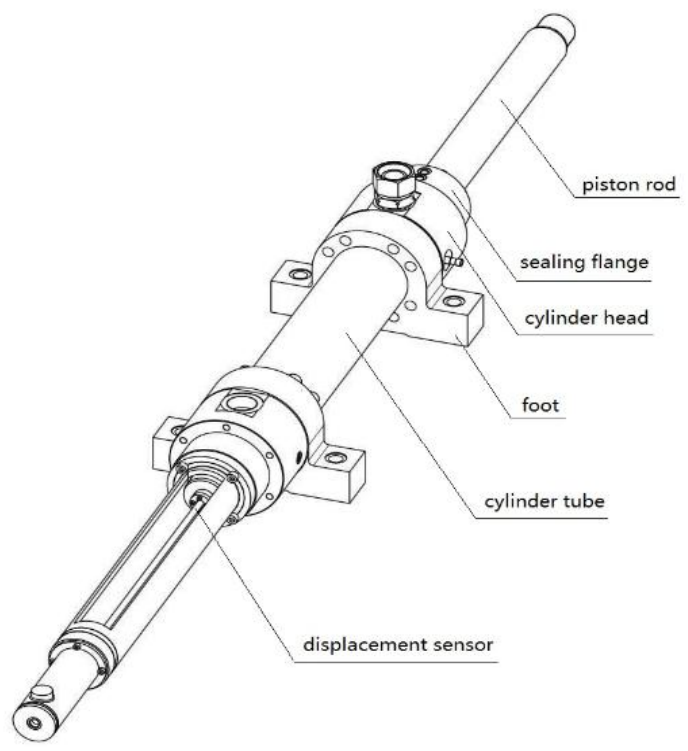

Figure 1. The double rod hydraulic cylinder

\subsection{The design of the control system}

The sealing system test requires to record the friction force caused by the test seal. Therefore, the pressure sensor in the two chambers of the device is installed to test the pressure change of the two chambers of the recording device. At the same time, the speed of the hydraulic cylinder is controlled and the stroke range of the movement can be adjusted, also need to achieve the precise positioning of the hydraulic cylinder movement control, so the displacement sensor signal needs to be sent to the test device, as a reference, control the high frequency alarm valve input signal, through the high frequency alarm valve signal adjustment to achieve the hydraulic cylinder movement position and speed control. Bosch Rexroth's electro-hydraulic controller $\mathrm{HNC}$ is chosen to meet the requirements of motion control and high-speed data acquisition and storage, according to the type and quantity of signal acquisition and the requirements of motion control. The control system frame is shown in Figure 2 .In the control system, the electrical components information is as the Table 1.

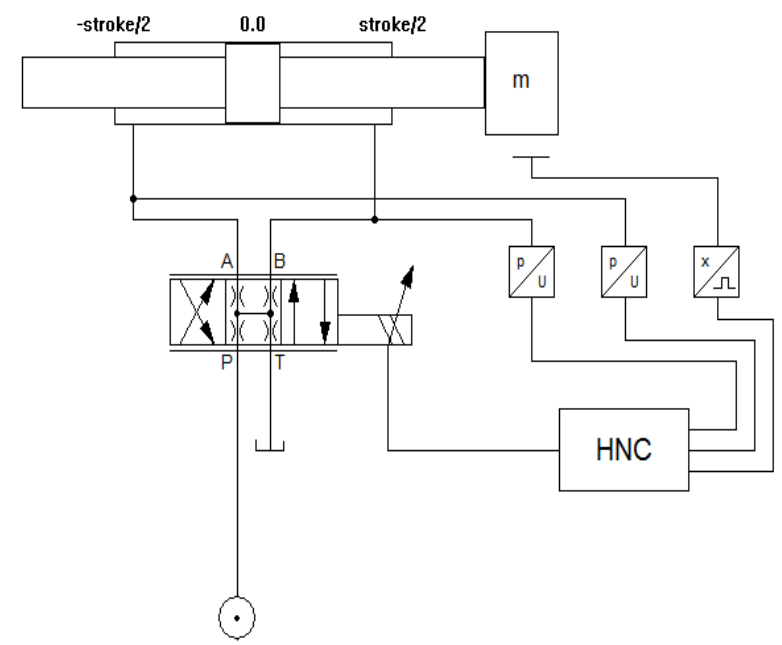

Figure 2. The control system frame
Table 1. The Selection electrical components

\begin{tabular}{|l|l|l|}
\hline $\begin{array}{l}\text { Electrical } \\
\text { Components }\end{array}$ & Model & Range \\
\hline Pressure sensor & HM20 & $\begin{array}{l}0 \sim 50 \mathrm{Bar} \\
4 \sim 20 \mathrm{~mA} \\
\text { Output }\end{array}$ \\
\hline $\begin{array}{l}\text { Displacement } \\
\text { sensor }\end{array}$ & $\begin{array}{l}\text { RH-M-0500-M- } \\
\text { D60-1-A01 }\end{array}$ & $\begin{array}{l}500 \mathrm{~mm}, \\
4 \sim 20 \mathrm{~mA} \\
\text { Output }\end{array}$ \\
\hline HNC & VT-HNC-2-3X/P- & $\begin{array}{l}\text { Two-axis } \\
\text { HNC with } \\
\text { TCP/IP } \\
\text { interface }\end{array}$ \\
\hline $\begin{array}{l}\text { High frequency } \\
\text { Response Valve }\end{array}$ & $\begin{array}{l}\text { 4WRTEV125L- } \\
\text { 4X/6E24K31A1 }\end{array}$ & $\begin{array}{l}\text { Input } \\
\text { Signal } \\
10 \sim 10 \mathrm{~V}\end{array}$ \\
\hline
\end{tabular}

\subsection{Introduction of the two kinds of sealing system}

At present, in hydraulic cylinder design, we usually take the series seal. In the present industrial applications, the detailed and suitable application that using the different sealing systems is not clear. In this paper, the common piston rod seal system includes M-sealing system and Tsealing system are taken test to compare the friction force in different speed with the same test condition. As shown in the Figure 3, M-sealing system is usually constituted with a stepseal, a u-ring and a wiper scraper seal ${ }^{[10-12]}$. As shown in the Figure 4, T-sealing system is usually constituted with two stepseals and a wiper scraper seal. And because of the limitation of time and experimental conditions, the $\mathrm{V}$-sealing system can be tested in later study.

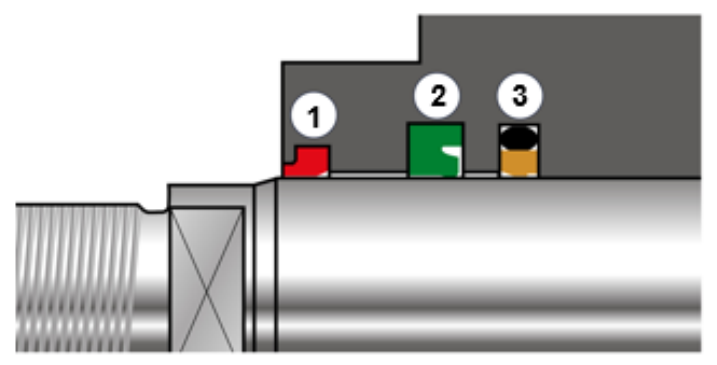

1-Wiper scraper seal, 2-Lip ring, 3-stepseal

Figure 3. The M-sealing system

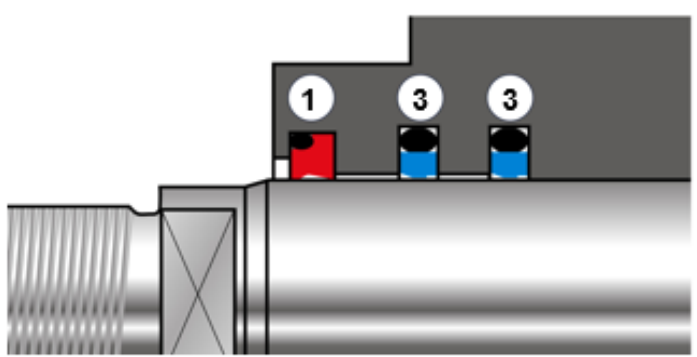

1-Wiper scraper seal, 2-Lip ring, 3-stepseal

Figure 4. The T-sealing system 


\section{Experimental}

Aimed at the different working conditions, such as stable working condition, high frequency working condition, working condition with pressure-holding requirement and the working condition with friction requirement, now, do research on the fiction and sealing performance of the $\mathrm{M}$ sealing system and the T-sealing system to find out the most appropriate occasion.

The research done on fiction at the specified sealing system, mainly test the friction force caused by seals of hydraulic cylinder. To do this experiment, we install the pressure sensors in the two cavity pressure joints of the double rod hydraulic cylinder and write the programs in HNC. Predict the fiction value by analyzing the friction curve in different speed, and layout them in the same cure, compared the curves in the two sealing systems in the last. Considering the actual situation of the hydraulic power unit, we choose the test pressure as 50Bar, and control the speed at $150 \mathrm{~mm} / \mathrm{s}, 150 \mathrm{~mm} / \mathrm{s}, 200 \mathrm{~mm} / \mathrm{s}$ and $250 \mathrm{~mm} / \mathrm{s}$ to get the curves.And the actual experimental equipment is shown as Figure 5.

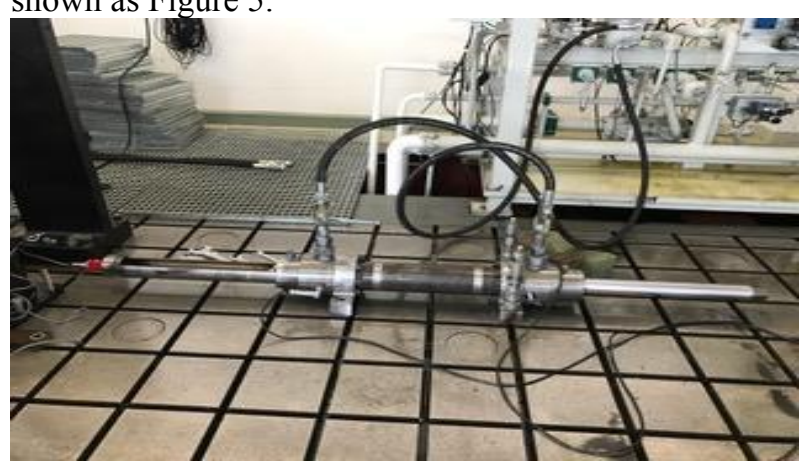

Figure 5. The double rod hydraulic cylinder photo

\section{Results and discussion}

In this experiment, we get the pressure valve in different speed by the pressure sensor installed in the pressure joints of the sealing flange, and through the scale conversion, we can finally achieve the real-time friction force.

\subsection{The Friction of M-sealing system}

When the pressure is 50 Bar, and the speed is $100 \mathrm{~mm} / \mathrm{s}$, the friction curve is shown as Figure 6.

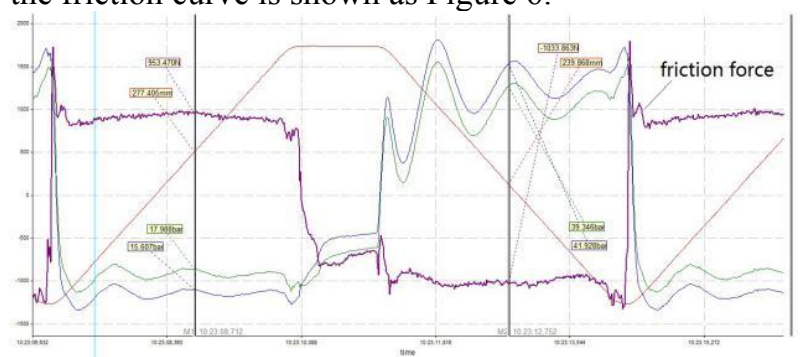

Figure 6. The friction curve in $100 \mathrm{~mm} / \mathrm{s}$ of M-sealing system

In above picture, the purple curve represents the change of friction force. In the process and return, take a symmetric position relatively.
From the friction force curve, the process friction is $953.470 \mathrm{~N}$, the return friction is $1033.863 \mathrm{~N}$, we can estimate the comprehensive friction is $993.667 \mathrm{~N}$.

With the speed of $150 \mathrm{~mm} / \mathrm{s}, 200 \mathrm{~mm} / \mathrm{s}$ and $250 \mathrm{~mm} / \mathrm{s}$, the friction curves are shown as Figure 7, Figure 8 and Figure 9.

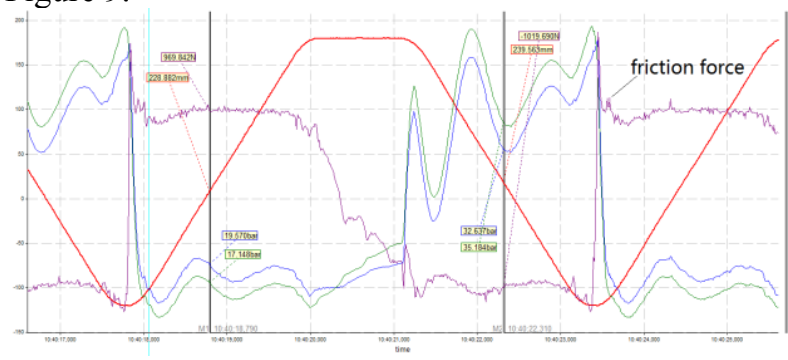

Figure 7. The friction curve in $150 \mathrm{~mm} / \mathrm{s}$ of M-sealing system

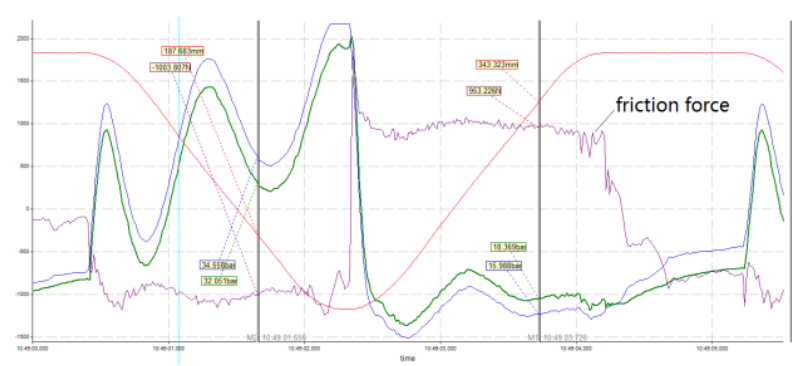

Figure 8. The friction curve in $200 \mathrm{~mm} / \mathrm{s}$ of M-sealing system

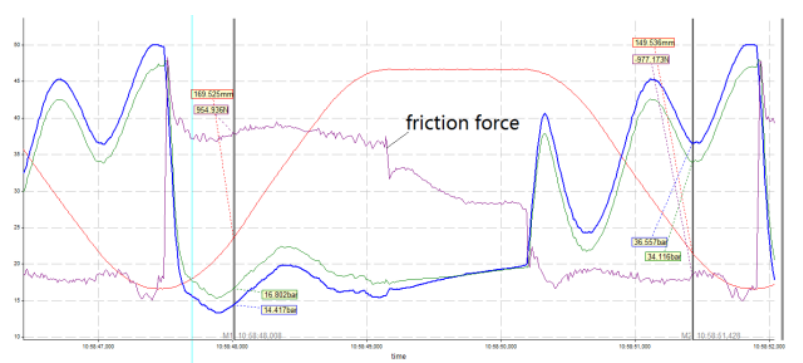

Figure 9. The friction curve in $250 \mathrm{~mm} / \mathrm{s}$ of M-sealing system

For ease of comparing the shape of the curves in different speed, put the average friction force in one curve by data analysis software, the detailed shape is shown as Figure 10.

In the shape of friction force in different speeds, with the higher speed, the friction force is generally a downward trend, but in the speed of $150 \mathrm{~mm} / \mathrm{s}$, it presents a rising friction value. Maybe it can attribute to the accuracy of the pressure sensor, in addition, the whole test system is designed artificially, and it also exists system error.

From the above curves, we know that the higher speed, the lower friction force. Meanwhile, in the Msealing system, the average friction force is $983.251 \mathrm{~N}$. 


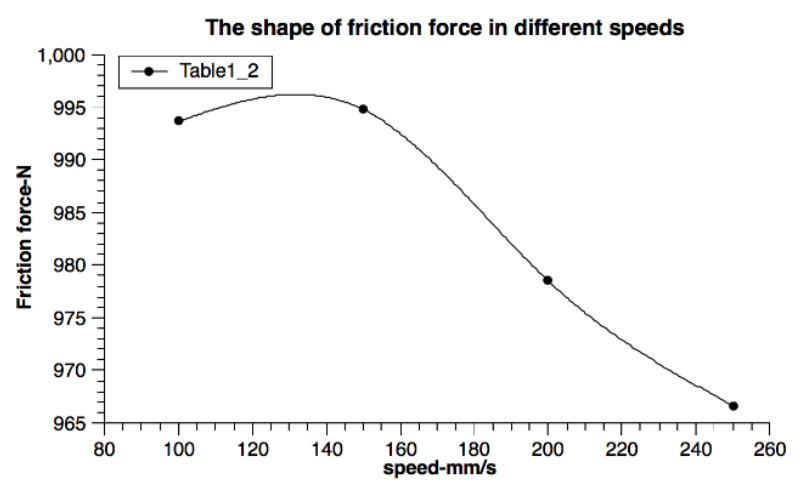

Figure 10. The shape of friction force in different speeds in Msealing system

\subsection{The Friction of T-sealing system}

In the T-sealing system, the friction curves in the speed of $100 \mathrm{~mm} / \mathrm{s}, 150 \mathrm{~mm} / \mathrm{s}, 200 \mathrm{~mm} / \mathrm{s}$ and $250 \mathrm{~mm} / \mathrm{s}$ are shown as Figure 11, Figure 12, Figure 13 and Figure 14.

Put the average friction force in one curve by data analysis software, the detailed shape is shown as Figure 15.

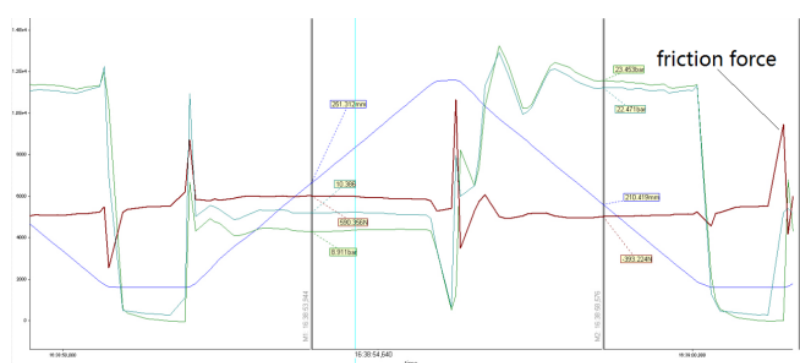

Figure 11. The friction curve in $100 \mathrm{~mm} / \mathrm{s}$ of T-sealing system

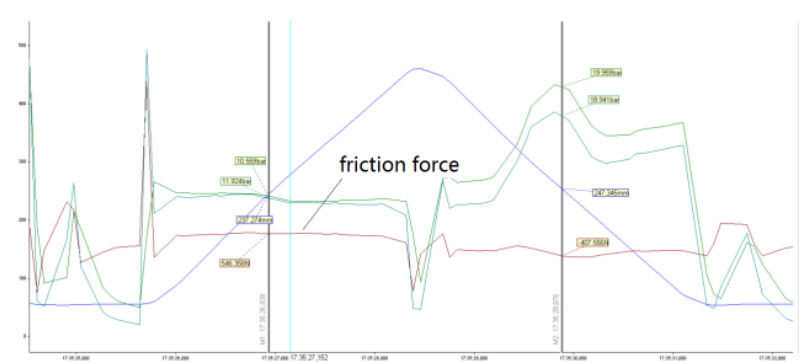

Figure 12. The friction curve in $150 \mathrm{~mm} / \mathrm{s}$ of T-sealing system

From the above curve, the general trend in the $\mathrm{T}$ sealing system is as the trend in the M-sealing system. The higher speed, the lower friction force. Meanwhile, in the M-sealing system, the average friction force is $476.702 \mathrm{~N}$.

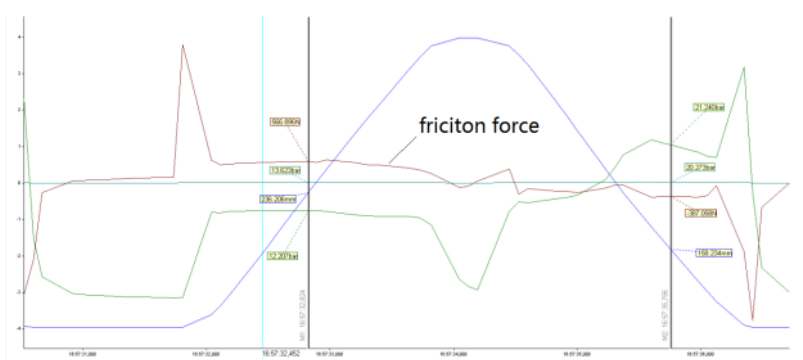

Figure 13. The friction curve in $200 \mathrm{~mm} / \mathrm{s}$ of T-sealing system

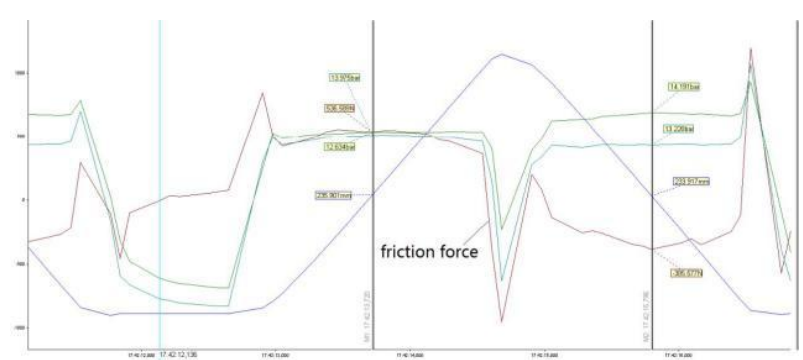

Figure 14. The friction curve in $250 \mathrm{~mm} / \mathrm{s}$ of T-sealing system

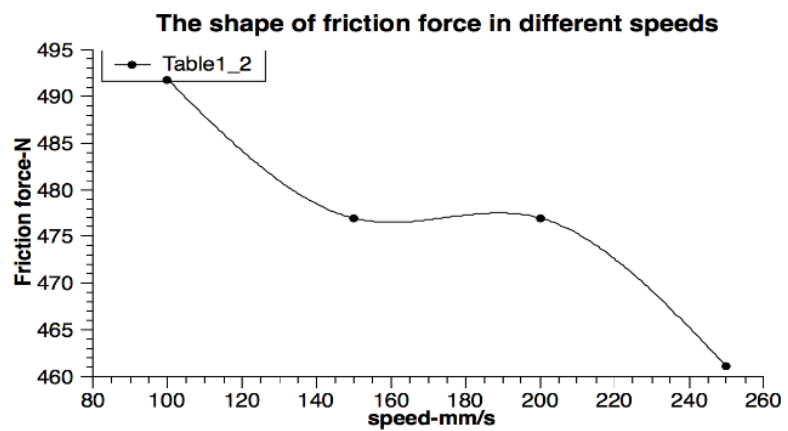

Figure 15. The shape of friction force in different speeds in Msealing system

By comparing the friction force curves in the two kinds of sealing system, the characteristics of the Msealing system and the T-sealing system are displayed. The M-sealing system has the following characteristics: durability, high strength, sensitive dust and well dust prevention. And the T-sealing system has an obvious advantage, that is low friction (with no crawling).

\section{Conclusions}

With the increasing application of hydraulic cylinder in industrial engineering, the design of cylinder is more reasonable, and the process technology is better perfect. The difficulty in design of hydraulic cylinder is the sealing system, because the failure of hydraulic cylinder mostly attributed to the failure of the seals. Therefore, take a study in sealing system and own a technical standard in selection of the sealing system is feasible.

Through the experiment, the most suitable applying situation of the different sealing systems is clear and definite. In the design of hydraulic cylinder, the Msealing system should be chosen in the steady conditions, and in the working condition of high frequency, the $\mathrm{T}$ sealing system should be considered. The research results provide the technical support in seals choosing, and meanwhile, with the requirement of friction predict, the experimental study can give the data support.

\section{Acknowledgements}

This research was supported by the the Natural Science Foundation of Jiangsu Province(Project No. BK20140247)and the Postgraduate Research \& Practice Innovation Program of Jiangsu Province (Project No. SJCX17_0161). 


\section{References}

1. X.L. Xu, W.S. Wei . Hydraulic Cylinder and Its Design. National Defense Industry Press, Beijing. (2011)

2. X. Zhou, L. Jiang, J. Gao. Simulation analysis for inner leakage of hydraulic cylinder based on amesim. Machine Tool \& Hydraulic, 40, 23, 147-150 (2012)

3. S.J. Shen, Q.H. Yang. Analysis and solution of hydraulic cylinder's leakage problem. Advanced Materials Research, 189-193, 664-667 (2011)

4. X.X. Zhao, S.S. Zhang, C.L. Zhou, Z.M. Hua, R. Li, J.H. Jiang. Experimental study of hydraulic cylinder leakage and fault feature extraction based on wavelet packet analysis. Computers \& Fluids, 106, 33-40 (2015)

5. W. Wang. Analysis on the side leakage amount of the friction between piston and cylinder block in axial piston pump. Applied Mechanics and Materials, 635-637, 341-345 (2014)

6. C.Y. Liu, F. Li. The design of seal style for the long journey hydraulic cylinder. Lubrication Engineering, no. 2, 167-169 (2005)
7. Y.D. Tang. Hydraulic Cylinder Seal Technology and Application. Machinery Industry Press, Beijing.(2016)

8. E.Z. Yang. Prospect of Modern Hydraulic Transmission Technology. Hydraulics Pneumatics \& Seals, no. 4, 1-6 (2003)

9. X. Zhang, Y. Bai, F. Zhang, P. Zhao. The research of performance testing system of sealing washer worked upright column for hydraulic support. Hydraulics Pneumatics \& Seals, no. 5, 39-42 (2012)

10. Z.D. Hu, J.H. Jiang. Friction torque of rotating hydraulic cylinder with deep circular groove oil film face seal. Advanced Materials Research, 97-101, 1937-1941 (2010)

11. G.B. Yu, B. Dai, L. Huang, J.F. Nie, Y. Zhao. Nocontact hydraulic dynamic seal characteristic study base on cfd. Applied Mechanics \& Materials, 274, 612-615 (2013)

12. G.D. Buyalich, K.G. Buyalich. Comparative analysis of the lip seal in hydraulic power cylinder. Applied Mechanics \& Materials, 770, 402-406 (2015) 